\title{
Research on the Application of the Discourse Analysis Theory in English Reading Teaching in Higher Vocational Colleges
}

\author{
Lianchun Zhang \\ Faculty of Foreign Languages ASEAN International Faculty, Kunming Metallurgy College, Kunming \\ 650033, China
}

Keywords: the discourse analysis theory; higher vocational colleges; English reading teaching; specific application

\begin{abstract}
In the existing subject system of higher vocational colleges, English is supposed to be the core and key subject. However, it has been a fact for a long time that many students of higher vocational colleges are lost or even tired in face of English reading. The root cause is that students do not pay close attention to discourse analysis and therefore lack a high-level ability of comprehensive analysis. Therefore, in order to improve the existing current state from the source, higher vocational colleges should focus on the overall optimization of the existing reading teaching, ensure the full integration of discourse analysis in the whole reading class and improve the overall classroom standard based on specific conditions.
\end{abstract}

\section{Introduction}

Fundamentally speaking, the reading skill should constitute a kind of key English skills. The new curriculum reform is embarking on an all-round promotion in recent years, and thus the existing reading mode of English also urgently needs to be fully improved. However, as of now, the existing effects of English classroom teaching still remain at a relatively low comprehensive level and the reading foundation of students is also very weak. Due to the strong impact of exam-oriented ideas, many teachers and students of higher vocational colleges are still limited to the superficial teaching and after-class exercises of reading materials. Therefore, there is a great possibility that the above mode may suppress students' enthusiasm for English reading and it is urgent to conduct a comprehensive transformation. In view of that English reading itself contains a variety of complex elements, teachers and students should be committed to improving their existing mode of reading and learning combining with text analysis.

\section{The Basic Principle of Discourse Analysis}

The discourse analysis principle refers to that the reader focuses on the statements of the overall discourse and pay more attention to the internal relations between paragraphs and sentences. Therefore, it can be seen that discourse analysis tends to focus on the English discourse with high integrity while not ignoring key and core paragraphs and words. On the premise of oral communication, the application of discourse analysis can help to broaden students' present range of oral communication, instead of simply explaining the exercises in narrow scope. Through the application of a comprehensive approach, students can have a deep induction and comprehension to the overall discourse effect and then generate an evaluation more viable.

Therefore, the basic principle of discourse analysis can closely integrate the causality of incidents, personality of characters and other key words with each other, and then helps readers conclude the related writing skills and core discourse ideas. Compared with the reading analysis of the traditional mode, the new reading thought based on the discourse analysis theory pays more attention to the language function and external language form, thereby cultivating students' ability of acquiring the information of the discourse comprehensively. After going deep into a particular type of discourse, students should closely integrate their existing overall cultural background to ensure a comprehensive understanding from the perspective of linguistic analysis. 
Language communication itself has significant dynamic characteristics, which usually involves all kinds of related terms, English vocabulary and other diverse oral expressions. Therefore, teachers shall turn their attention to discourse analysis in the current English classroom, so as to enable students to thoroughly understand the various related phenomena. The focus of discourse analysis is to improve students' existing ability of inference and comprehensive induction, rather than a detailed study of a specific type of statements. The use of measures above is supposed to reinforce the overall awareness at the root cause.

Specifically speaking, discourse analysis usually involves the analysis of the overall discourse structure as well as the consistency and coherence of terms. The application of all-around discourse analysis can optimize the overall awareness of discourse that students have and activate the latent self-exploration awareness. On the premise of following the basic purpose of discourse analysis, it is necessary to ensure that comprehensive means and measures are applied to encourage students to think independently. Therefore, discourse analysis is a guarantee of enhancing the sense of discourse and optimizing the overall atmosphere of reading in class.

\section{The Existing Difficulties and Shortcomings in English Teaching}

From the perspective of the fundamental purpose, the most crucial thing for higher vocational colleges is to cultivate qualified personnel with practical qualities. In the field of English subject, it is needed to proceed with the optimization of the existing reading class so as to ensure the full application of the new mode of reading class. In recent years, higher vocational colleges are taking employment orientation as the key to optimizing classroom processes. However, in general, many of them still lack comprehensive control and understanding in the face of certain types of English discourse, and cannot obtain relevant discourse information in a relatively short period of time. Specifically, the classroom loopholes in English reading as well as the defects of the classroom mode are reflected as follows:

\subsection{Unilateral Attention to Answer Questions}

In the traditional mode, teachers and students usually only pay attention to answer questions attached reading materials. From the viewpoint of many teachers and students, students complete all the tasks of classroom if they can properly finish the exercise attached to corresponding reading materials. However, the above-mentioned understanding is unilateral. The root cause is that teachers and students are too concerned about the correct solution to some post-class problems, and thus they are likely to neglect the comprehensive understanding of the discourse while highlighting reading skills.

In the current classroom process, many teachers also tend to focus on difficult phrases, English words and sentences, but neglect to enumerate specific examples. Affected by the classroom mode mentioned above, students usually tend to highlight the correct probability of problem solving, but they do not achieve full control from the perspective of the entire discourse. Due to the lack of full interaction, higher vocational students may only passively memorize some discourse knowledge taught by teachers and thus are unable to arouse their potential interest in reading and exploring.

\subsection{Lack of Comprehensive Grasp of the Discourse}

Any type of discourse should be integral while English discourse itself is a whole part with high integrity. However, in essence, teachers and students in higher vocational schools now still lack the grasp of discourse in the reading class and neglect the essential integrity. For example, in the existing classroom process, teachers usually teach their students specific types of wording and also select some of the core words to ask the students to identify and remember. Therefore, students may be in a unilateral discourse understanding if they neglect the overall grasp of the whole discourse. In addition, the simple understanding of certain words or memory of certain phrases is also not conducive to enhancing students' comprehensive reading skills.

Students tend to repeatedly read some difficulties involved because too much attention is given to the details of reading discourse. Influenced by the status quo mentioned above, the entire reading class can not reflect its due high-level reading effectiveness. It now appears that some higher 
vocational students remain in the relatively weak foundation of English. As a result, they are likely to feel inferior or afraid in the face of relevant knowledge in reading classes. And they may even lose their interest in reading classes in the long run. In fact, teachers can fundamentally reverse the current state of students' English learning if they can guide them to thoroughly understand the whole discourse.

\subsection{Simplistic and Rigid Classroom Atmosphere}

The lack of close interaction between teachers and students is likely to lead to a simplistic or rigid atmosphere of English classes. At present, many vocational students have a weak foundation of English and thus they crave recognition and concern from teachers and other students. However, many English teachers in higher vocational colleges have not really perceived the mentality of students up to now and also cannot provide them with necessary learning enthusiasm or learning motivation. Affected by the rigid classroom atmosphere, many vocational students tend to ignore their existing learning loopholes and do not have the motivation to improve themselves.

There are still many students who tend to understand reading materials by translating word by word with the support of a dictionary in current reading classes. Once they encounter difficult details, they will have to spend relatively more time in reading. Sometimes, students may even exclude reading classes, which is detrimental to achieving good effectiveness of learning in reading. In daily reading classes, there are also many students tending to sit in the back rows and like to delay or skimp reading assignments.

\section{Specific Measures to Apply Discourse Analysis into English Reading Teaching}

For most of the higher vocational students, it takes them a relatively long time to optimize their own reading literacy at their source. Therefore, in addition to reading training, they must strive to broaden their reading horizons to achieve this goal. From the current practical point of view, teachers are supposed to assist their students to set their future reading plans in English. And at the same time, students need to provide related reading reports after completing the full-text reading, instead of simply translating sentence by sentence or word by word. In reading practice at the current stage, the following elements should be valued so as to make students fully integrate into discourse analysis:

\subsection{To Thoroughly Change the Cognition of Discourse Reading}

Many students of higher vocational colleges now still have shallow discourse comprehension and it is necessary for them to improve their present cognition of discourse reading in all aspects. At present, higher vocational students show poor reading ability and less vocabulary. In the meantime, teachers tend to translate texts sentence by sentence for their students in the current English classroom while ignoring the omnibearing grasp of the discourse. Compared with the reading mode which focuses solely on English words and sentences, the discourse analysis mode therefore has more remarkable effectiveness and can rapidly improve the reading ability of students.

In addition, many teachers and students in higher vocational schools find text analysis ineffective in improving their existing English reading scores and tend to neglect it. Teachers should guide students to achieve the deep transformation of train of thought in order to optimize the status quo from the root causes. In essence, if students can pay more attention to the whole discourse instead of confining their own reading perspective to superficial sentence analysis or lexical judgment, they will be able to obtain a more significant overall reading effect and speed up their own existing reading exercises.

\subsection{To Combine Cultural Backgrounds Closely}

At present, many students lack the interest in English reading. The root cause lies in the fact that they do not closely integrate discourse in the specific cultural background and neglect the potential cultural differences. In view of the above situation, teachers must fully integrate reading materials into the specific cultural background, in order to stimulate students' keen reading interest from the overall perspective of cultural background. The cultural background closely related to reading class should include the author's life, creative thinking and local culture. The deeply exploration of the 
cultural background involved should help grasp the clue of the reading discourse and involve some deep-seated and hidden connotations.

However, up to now, teachers and students have not really paid attention to the whole background of reading discourse and also cannot get the hidden contents, mainly because many teachers are confined to a relatively narrow horizon of reading and lacking in extensive knowledge. In this sense, teachers can collect videos or short videos by the way of informatization to ensure that they are inherently related to discourse in the current teaching process. After a full preparation, teachers can share fun videos collected in advance with their students in class. The application of such means of informatization should be able to broaden students' existing cultural perspectives and help them to thoroughly understand certain types of discourse.

\subsection{To Pay Attention to Multi-Level Reading Skills of Discourse}

The reading skills of discourse contain a relatively wide range, which involves multi-level reading skills. Students are likely to read with very rigid train of thought if they lack comprehensive reading skills. Influenced by the principle of discourse analysis, many teachers and students in higher vocational colleges are paying attention to reading skills. Typical reading skills should include rhetoric, text composition and other relevant skills. For example, some reading materials use language skills such as exaggeration, metaphor or satire, and students should identify the real connotation by surface semantics. Only by paying close attention to the language skills can students not fall into a particular reading misunderstanding.

In addition, teachers should guide their students to thoroughly understand the key paragraphs and words in order to quickly complete related exercises attached to corresponding reading materials. For example, in recognizing certain types of keywords, attention should be given to thematic sentences or other types of keywords. However, some higher vocational students have relatively little vocabulary, and teachers are supposed to introduce more English vocabulary to this type of students, so that they can understand sentence groups more accurately in the face of the entire discourse. In face with some uncommon words or difficult words, students can skip appropriately, rather than spending valuable time in understanding them.

\section{Summary}

Based on the comprehensive analysis, it can be known that the implementation of discourse analysis is the key if students want to fundamentally improve their existing reading literacy. This is because using the means and measures of discourse analysis helps to improve the reading mode and ensure that new reading thoughts are incorporated into the reading. Therefore, in the future related reading practice of English discourse, teachers and students need to completely change their focus, so as to ensure that they can accept the fundamental principle of discourse analysis and new reading mode. On the premise of writing reading reports and enhancing the overall understanding of reading materials, higher vocational colleges will achieve better overall English reading teaching to enhance students' comprehensive reading ability.

\section{Acknowledgements}

Funded project: Study of the Strategy Improving students' English Reading Ability in Higher Vocational Colleges from the Perspective of "Interaction" -- This work was supported by a grant from the scientific research fund of Kunming Metallurgy Colleges (No.: 2017xjsk07)

\section{References}

[1]. Wang Chunyan. The Application of Text Analysis in English Reading Teaching at Higher Vocational Colleges [J]. Journal of Puer University, 2016, 32 (05): 109-111.

[2]. Lan Shanfang. The Application of the Discourse Analysis Theory in English Reading Teaching of Senior High Schools [J]. English Teachers, 2015, 15 (23): 9-10. 
[3]. Huang Mujian. On the Application of the Cohesion and Coherence Theory in English Teaching at Higher Vocational Colleges [J]. English Square (Academic Research), 2013 (05): 86-87.

[4]. Long Donglin. Study of the Effectiveness of Discourse Analysis in Public English Reading Teaching [J]. New West (Theory Edition), 2012 (Z3): 40-41.

[5]. Luo Hairong. Discussion on the Application of Discourse Analysis in English Reading Teaching of Vocational College [J]. Journal of Qiongzhou University, 2011, 18 (01): 165-166.

[6]. Li Fang. A Probe into the Teaching Mode of English Reading Discourse in Higher Vocational Colleges [J]. New Curriculum Research, 2012 (10): 81-82.

[7]. Wu Xinyun. On the Use of Discourse Analysis in English Reading Teaching at Higher Vocational Colleges [J]. Journal of Heilongjiang Vocational Institute of Ecological Engineering, 2012, 23 (02): 123-124.

[8]. Wang Rui. Discourse Analysis in Teaching of Vocational English Reading [J]. Modern Science, 2012 (12): 231.

[9]. Wang Lin. Discourse Analysis and English Teaching in Vocational Colleges [J]. Journal of Shanxi Economic Management Institute, 2012, 17 (02): 117-118.

[10]. Liu Wenjuan. Application of the Discourse Analysis Theory in English Reading Teaching in Higher Vocational Education [J]. The Science Education Article Collects, 2017 (03): 57-58. 